Bull. Mater. Sci., Vol. 21, No. 4, August 1998, pp. 329-333. (C) Indian Academy of Sciences.

\title{
Estimation of composite strength by a modified rule of mixtures incorporating defects
}

\author{
B K SARKAR \\ Department of Material Science, Indian Association for the Cultivation of Science, Jadavpur, \\ Calcutta 700 032, India \\ MS received 4 May 1998
}

\begin{abstract}
Inadequacy of the rule of mixtures to estimate the true values of composite properties having a large concentration of defects has led to numerous tests being performed costing time and money. Statistical average of the properties from the Weibuls distribution law has thus been relied upon so far for the design of composite structures. Yet, to estimate the properties of a fibre reinforced composite material having sufficient flaw densities due to the methodologies adopted for its processing, more so for fibres, has long been appreciated. To avoid this inadequacy a modified rule of mixtures is developed incorporating defect concentration in the fibre and matrix enabling to arrive at a more realistic value of the composite.
\end{abstract}

Keywords. Rule of mixtures; glass and carbon fibre reinforced composites; fibre to matrix ratio; defect concentration; Weibull's failure probability.

\section{Introduction}

Estimating the composite strengths to design structures with composites by the basic rule of mixtures $\left(\sigma_{\mathrm{c}}=V_{\mathrm{f}}\left(\sigma_{\mathrm{f}}-\sigma_{\mathrm{m}}\right)+\sigma_{\mathrm{m}}\right)$, where $\sigma_{\mathrm{c}}$ is the composite strength, $V_{\mathrm{f}}$ the volume fraction of fibres and $\sigma_{\mathrm{f}}$ and $\sigma_{\mathrm{m}}$ are the strengths of reinforcing fibres and matrix, respectively has long been found inadequate. This has arisen out of the large difference observed between the estimated and the measured values. Padmanabhan and Kishore (1995) had demonstrated a large variation in the actually measured strength values of carbon fibre composites in contrast to the much higher estimated values. Such discrepancies are attributed to the large volume of defects in different forms and shapes introduced into the reinforcing and matrix materials forming the composite during processing. It assumes more relevance in the case of ceramic-ceramic composites for high temperature applications where the defect concentration like voids, cracks etc could be very large due to its consolidation from powders. Consequently, workers engaged in designing structures with composite materials have adopted their own criteria to accept the properties of the composites for their design. Chamis (1987) calculated micro-stresses for predicting the overall failure stresses in a composite. The work on the micro-mechanics of defects assumes more importance in this context. Chow and Kelly (1980) and Kelly and Mileiko (1983) laid more importance to the defect free processing to avoid unpredicted failures of composites. The role of defects arising out of irregular processing of a composite was further illustrated by Johnson and Ghose (1981). The concept of a weakest link theory introducing the probabilistic factor postulated by Weibull (1951) has thus remained a support to lean on for acceptance of a more reliable value in absence of an alternative. He proposed that the majority of experimental data for failure of brittle solids conforms to an equation of the form

$$
n_{0} L_{0}=\left(\sigma / \sigma_{0}\right)^{m}
$$

where $n_{\sigma}$ is the number of flaws per unit length of reinforcing fibre sufficient to cause failure under an applied stress $\sigma, \sigma_{0}$ the probable strength expected from a fibre of length $L_{0}$, and $m$ the Weibull modulus. Zweben and Rosen (1970), Jones (1975) and Spencer (1986) have remained proponents of the statistical approach in resolving the differences between the estimated and experimental values of composite properties. The statistical approach however, requires a large number of actual measured data which remains a prohibitive factor for cost and time.

Considering the unavoidable introduction of defects during processing of either fibre or composite, a modification to the rule of mixtures in accordance with the parabolic nature of the fibre strength with voids (Bailey and Barker 1971) is developed to estimate a more realistic value of composite properties avoiding a large number of tests.

\section{Types of defects in a composite}

Literature is replete with information on the origin of micro and macro defects in a composite affecting its 
properties seriously. The type of defects commonly seen is depicted schematically in figure 1. Defects like dislocations, grain boundaries applicable for metals are not considered here which otherwise add to the lowering of their properties further. The discovery of carbon fibres in mid sixties made from pitch, rayon and PAN activated developments of alternate fibres like $\mathrm{Al}_{2} \mathrm{O}_{3}, \mathrm{SiC}, \mathrm{Si}_{3} \mathrm{~N}_{4}$ fibres for high temperature composites. Appreciating the porous structure of a ceramic material arising out of powder consolidation, Bailey and Barker (1971) deliberately introduced various quantities of voids in $\mathrm{Al}_{2} \mathrm{O}_{3}$ fibres and correlated with their properties. The strength of the fibres they measured with varying porosities is shown in figure 2. It depicts the reduction in strength with increasing amount of defects introduced in the fibres. The drop had been very sharp initially then tapering off beyond $25 \%$. Similar effect was shown by Johnson (1980) on the contribution of resin matrices on composite shear strengths.

\section{Modified rule of mixtures}

By applying the basic rule of mixtures, composite strengths were estimated for $\mathrm{Al}_{2} \mathrm{O}_{3}$ fibre reinforced resin

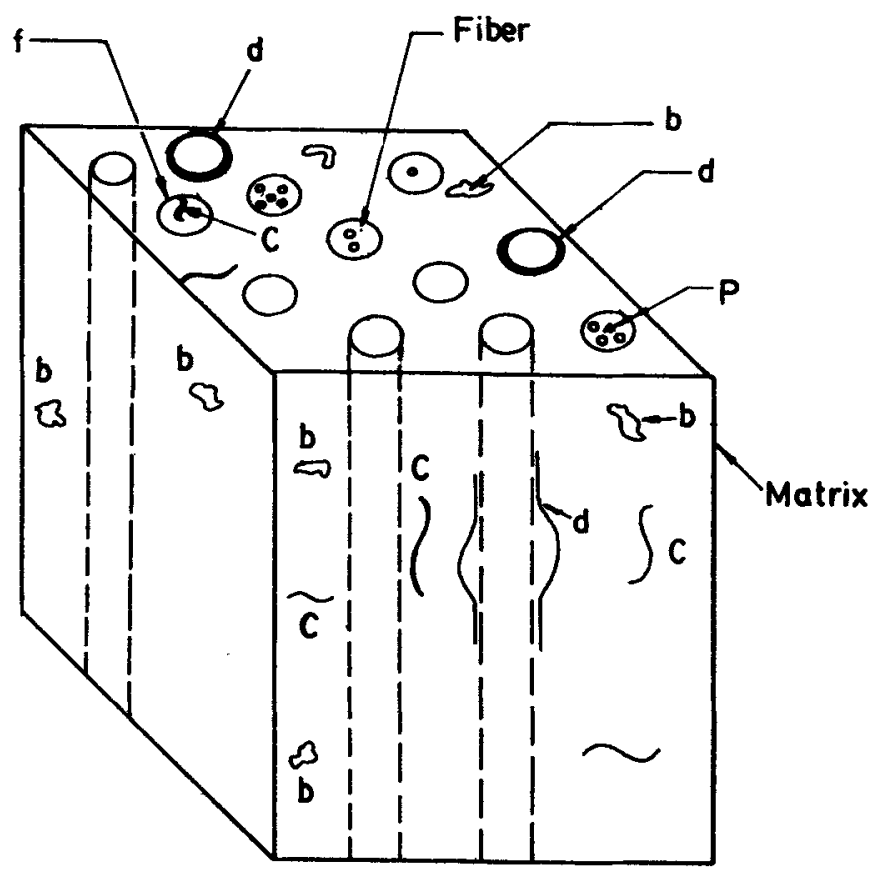

$$
\begin{aligned}
& \text { b- blowholes, } \\
& \text { C-cracks, } \\
& \text { d- debonding } \\
& \text { p- porosity } \\
& \text { f - Fiber }
\end{aligned}
$$

Figure 1. Schematic representation of defects normally present in a composite. matrix from the fibre strength values obtained from figure 2 at varying volume fractions of fibres with different volume fractions of defects. The estimated values are shown in figure 3 . The strengths of the composites were seen to drop sharply with increasing amounts of defects (porosities) and the effect is more predominant at higher volume fraction of fibres. The drop in strength is minimal at lower volume fraction of fibres. On replotting figure 3 , with strengths against volume fraction of fibres at different concentrations of defects, shown in figure 4 , a straight line relationship is illustrated having 0.82 as its highest slope at 0.05 and a shallow slope of 0.34 at 0.5 volume fraction defect concentration, respectively. This is represented as,

$$
\sigma_{\mathrm{c}}=m \cdot V_{\mathrm{f}}+\sigma_{\mathrm{m}}
$$

where $m$ is the slope of the curves dependent on the defect concentration/flaw densities in the fibres. Taking the different values of $m$ from figure 4 a logarithmic plot with $m$ against volume \% defects resulted in a straight line relationship given by

$$
\log m=\log n-k d,
$$

where $n$ is the strength of the defect free fibre, $d$ the volume fraction of defects in the fibre, and $k$ is the slope of the curve having a value of -0.98 . Rearranging (3) and substituting for $m$, the composite strength can be expressed as

$$
\sigma_{\mathrm{c}}=n e^{(-k i l)} V_{\mathrm{f}}+\sigma_{\mathrm{m}} .
$$

Similarly, accounting for the defect concentration in the

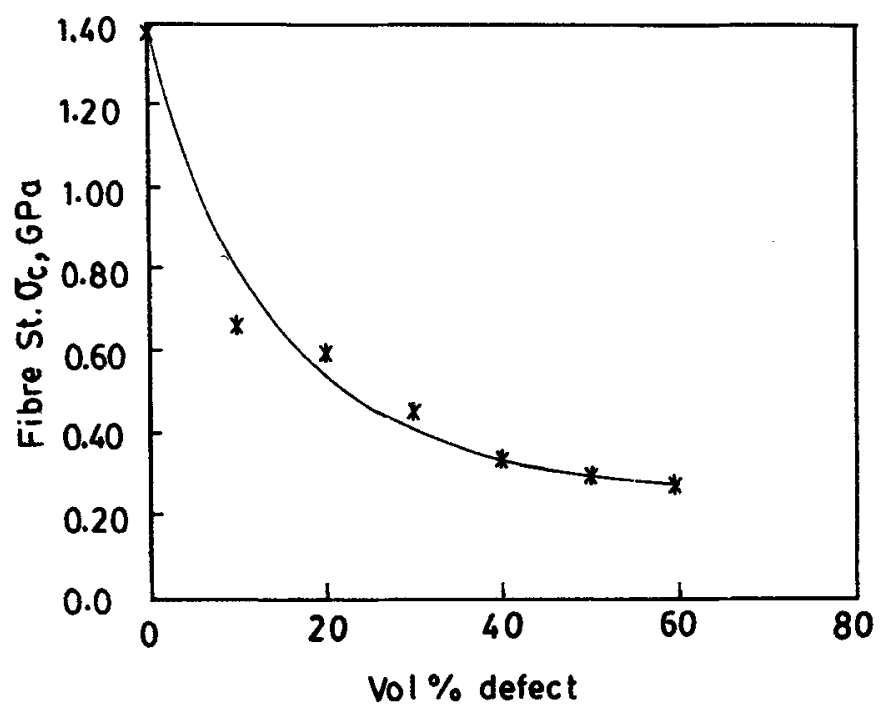

Figure 2. Strength of $\mathrm{Al}_{2} \mathrm{O}_{3}$ fibres with volume \% defects. 
matrix material like blowhole, debonding, cracks, etc the rule of mixtures thus gets modified into

$$
\sigma_{\mathrm{c}}=V_{\mathrm{f}}\left(n_{1} e^{-k d_{1}}-n_{2} e^{-k t_{2}}\right)+n_{2} e^{-k d_{2}},
$$

where $n_{1}$ and $n_{2}$ are fibre and matrix strengths at defect concentrations of $d_{1}$ and $d_{2}$, respectively, thus accounting for the defects invariably present in the materials.

\section{Fibre strengths}

Several methods were adopted to produce defect free

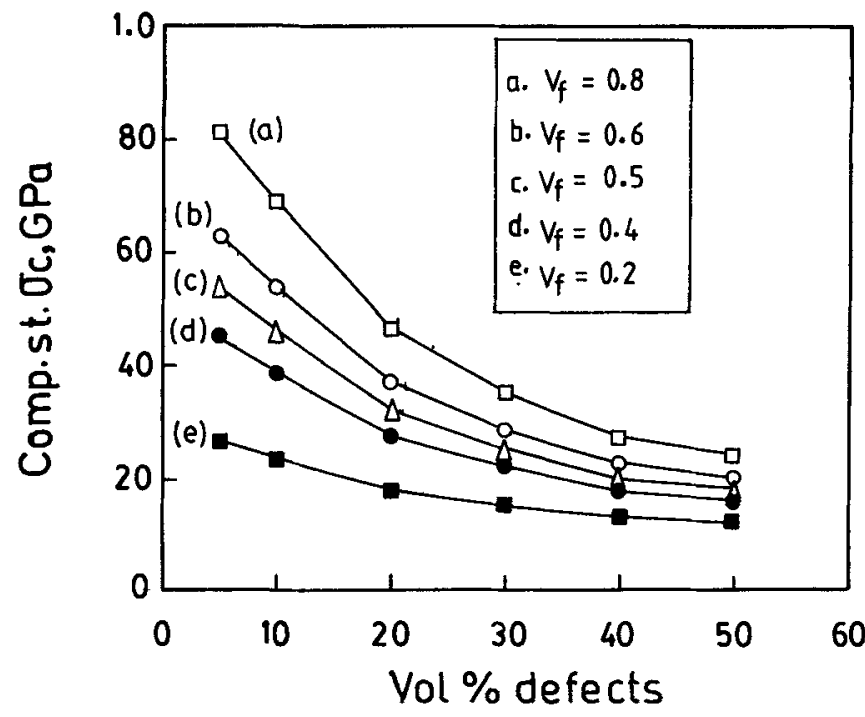

Figure 3. Strength variation of $\mathrm{Al}_{2} \mathrm{O}_{3}$ fibre reinforced composite with volume $\%$ defects at different volume fraction of fibres.

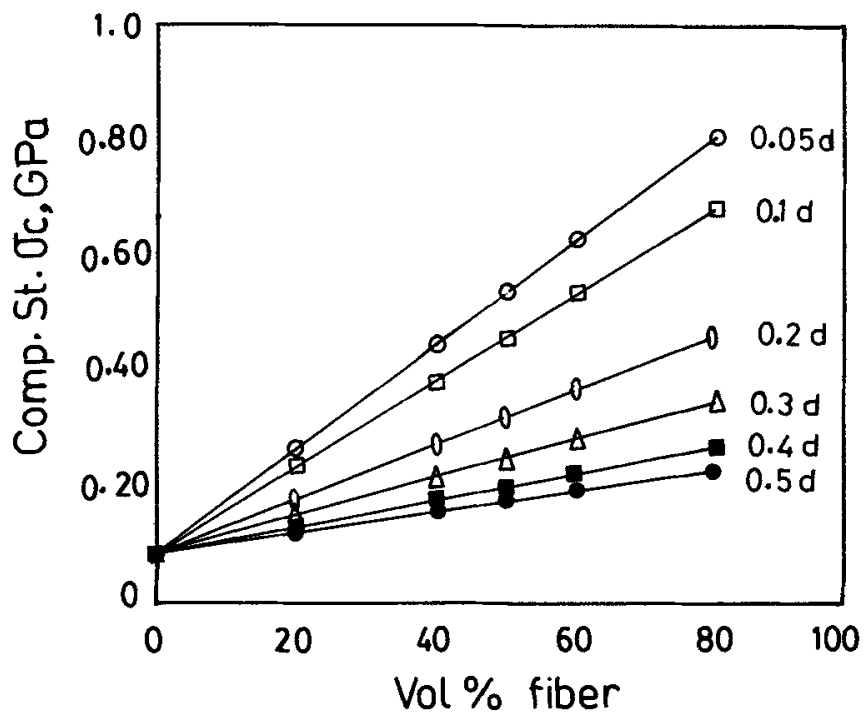

Figure 4. Strength variation of $\mathrm{Al}_{2} \mathrm{O}_{3}$ fibre reinforced composite with volume $\%$ fibres at different volume fractions of defects. fibres. Matsumoto (1985) reported several properties of carbon fibres produced from different precursors. A wide variation was evident. The most realistic strength values of materials generally accepted for preparing fibre reinforced composites is shown in table 1. Strengths of commonly employed resins is shown in table 2.

Composite strengths were estimated from (5) with varying \% of defects at different volume fractions of fibres, taking strength properties of carbon and $E$ glass fibres as $3.85 \mathrm{GPa}$ and $2.35 \mathrm{GPa}$, respectively, whilst $0.085 \mathrm{GPa}$ as epoxy resin strength.

Table 1. Strength of commercial fibres.

\begin{tabular}{lcl}
\hline Fibre & $\begin{array}{c}\text { Strength } \\
\text { (GPa) }\end{array}$ & \multicolumn{1}{c}{ Reference } \\
\hline E-glass & 2.35 & Gagin (1980) \\
Carbon & 3.85 & Matsumoto (1985) \\
Graphite & 4.22 & Matsumoto (1985) \\
Alumina & 1.38 & Dhingra (1980) \\
Silicon carbide & 2.31 & Yajima et al (1976) \\
Kevlar (TM49) & 3.07 & Black (1980) \\
Silicon nitride & 1.98 & Okamura et al (1987) \\
\hline
\end{tabular}

Table 2. Strength of commercial resins commonly used.

\begin{tabular}{lcl}
\hline Resin & $\begin{array}{c}\text { Strength } \\
(\mathrm{GPa})\end{array}$ & \multicolumn{1}{c}{ Reference } \\
\hline Epoxy & $0.035-0 \cdot 10$ & Monteiro (1986) \\
Polyester & $0.04-0.09$ & Muzzy and Kayo (1984) \\
Polypropylene & $0.02-0.04$ & Watkinson et al (1982) \\
PEEK & 0.07 & Muzzy et al (1984) \\
\hline
\end{tabular}

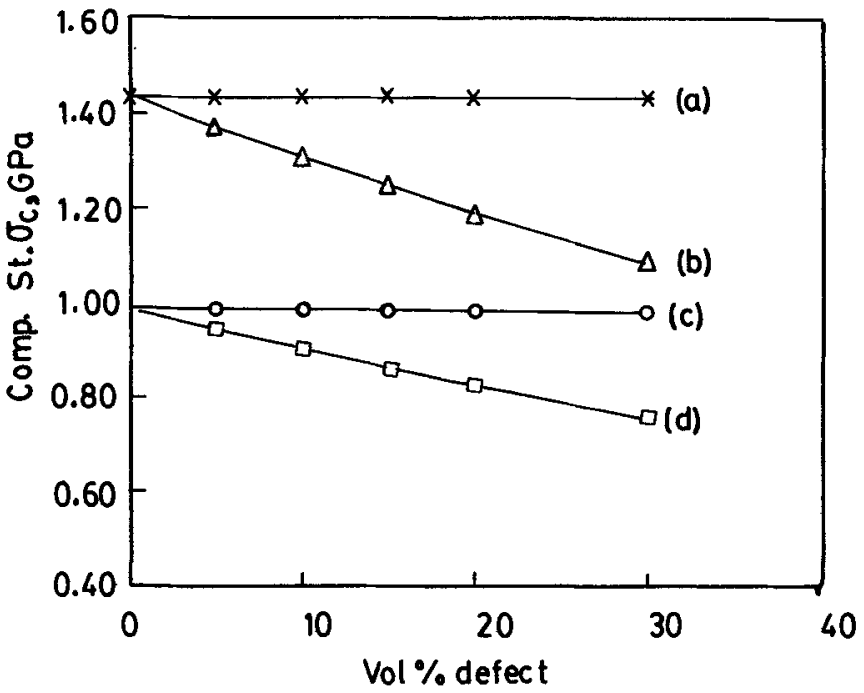

Figure 5. GFRP composite strengths against volume $\%$ defects at: (a) $d_{1}=0, V_{\mathrm{f}}=0.6$; (b) $d_{2}=0, V_{\mathrm{f}}=0.6$; (c) $d_{1}=0, V_{\mathrm{f}}=0.4$; (d) $d_{2}=0, V_{\mathrm{f}}=0.4$. 


\section{Strength estimation of GFRP and CFRP}

Figure 5 shows the composite strength properties derived from (5) with volume \% defects in $E$ glass fibre reinforced epoxy resin matrix (GFRP composite). Two properties are shown here at varying amounts of $d_{1}$ in the fibre with $d_{2}=0$ at $V_{\mathrm{f}}=0.6$ and 0.4 and vice versa. When the $V_{\mathrm{f}}: V_{\mathrm{m}}$ was high naturally the composite strength was also high. When $V_{\mathrm{f}}=0.4$ with defect free resin matrix

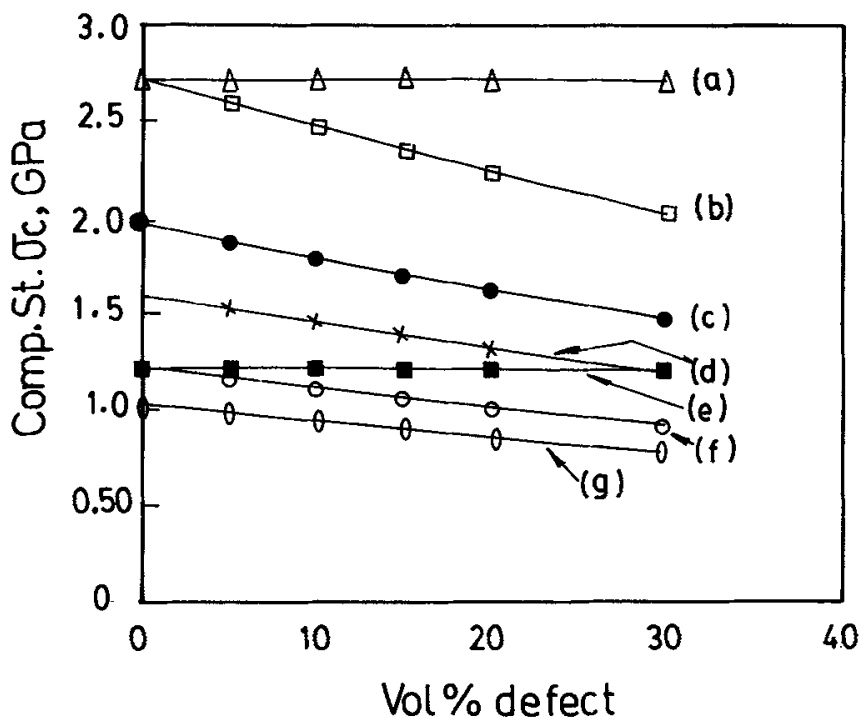

Figure 6. CFRP composite strengths against volume \% defects with varying volume fractions of carbon fibres at: (a) $d_{1}=0, \quad V_{\mathrm{f}}=0.7 ;$ (b) $d_{2}=0, V_{\mathrm{f}}=0.7$; (c) $d_{2}=0, V_{\mathrm{f}}=0.5$; (d) $d_{2}=0, V_{\mathrm{f}}=0.4$; (e) $d_{1}=0, V_{\mathrm{f}}=0.3$; (f) $d_{2}=0, V_{\mathrm{f}}=0.3$ and (g) $d_{2}=0, v_{\mathrm{f}}=0.25$.

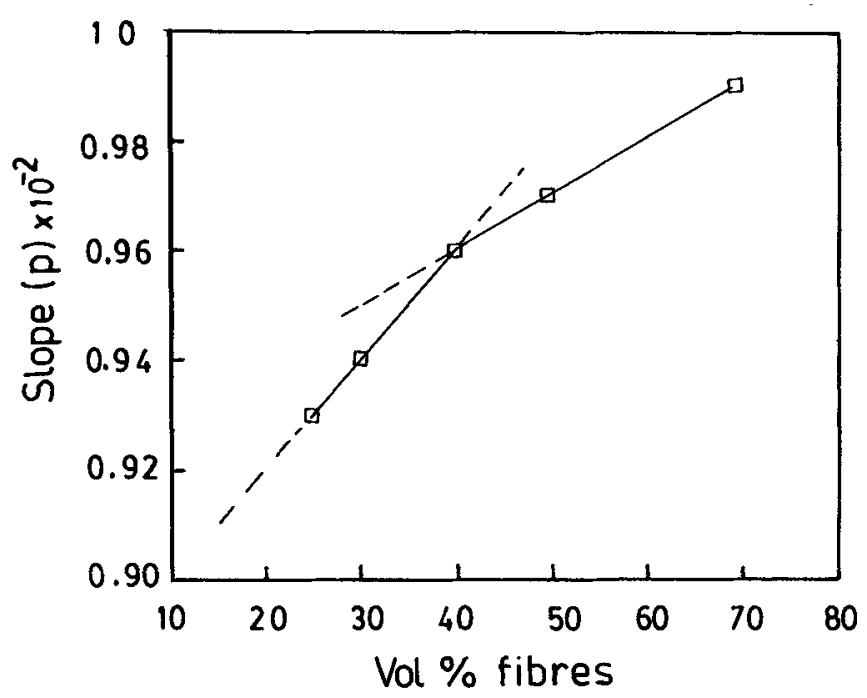

Figure 7. Slopes of CFRP composite strength variation against volume \% defects. $\left(d_{2}=0\right)$, the $\sigma_{c}$ dropped from $0.99 \mathrm{GPa}$ to $0.76 \mathrm{GPa}$; whereas at $V_{\mathrm{f}}=0.6$ the drop in $\sigma_{\mathrm{c}}$ was from $1.44 \mathrm{GPa}$ to $1.07 \mathrm{GPa}$. It was thus apparent that the defect concentration in the fibres has the maximum effect on the GFRP composites. The drop in strength was much sharper at higher fibre ratio. Whilst the defect concentration in the resin up to $30 \%$ could be accommodated without sacrificing $\sigma_{\mathrm{c}}$ with defect free fibres.

Similar effect was seen to occur in carbon fibre

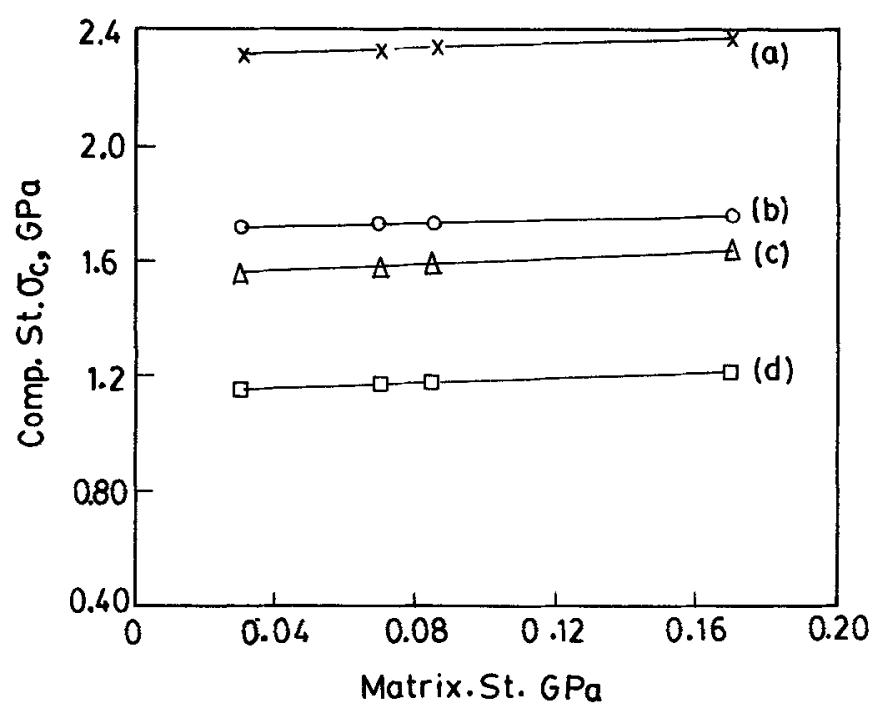

Figure 8. CFRP composite strengths with different resin matrix strengths. (a) $d_{1}=d_{2}=0, V_{\mathrm{f}}=0.6$, (b) $d_{1}=d_{2}=0, V_{\mathrm{f}}=0.4$, (c) $d_{1}=d_{2}=0.3, V_{\mathrm{f}}=0.6$ and (d) $d_{1}=d_{2}=0.3, V_{\mathrm{f}}=0.4$.

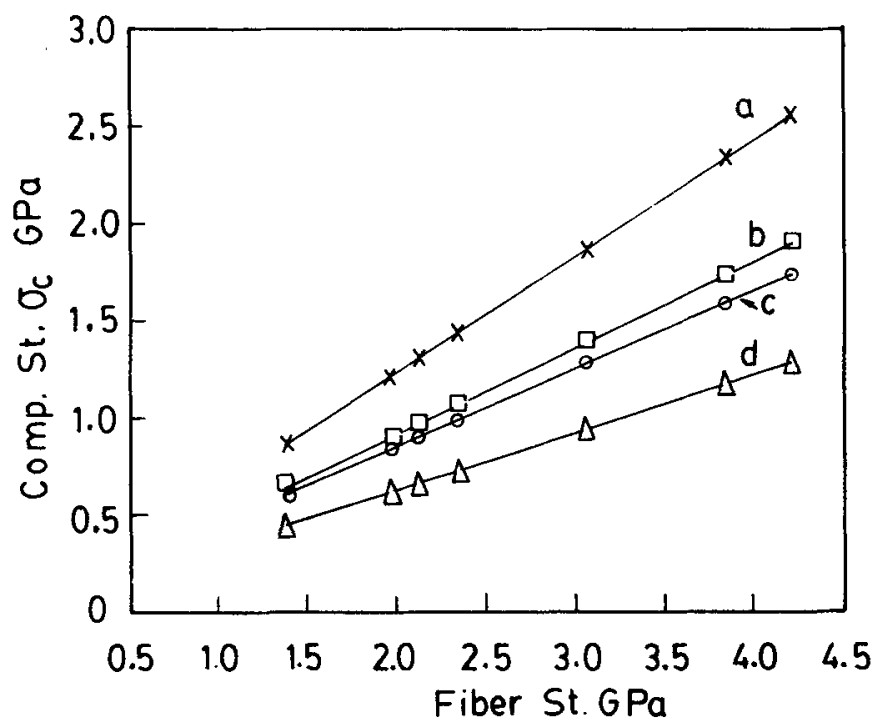

Figure 9. CFRP composite strengths with different fibre strengths in epoxy resin. (a) $d_{1}=d_{2}=0, V_{\mathrm{f}}=0.6$, (b) $d_{1}=d_{2}=0, \quad V_{\mathrm{f}}=0.4, \quad$ (c) $d_{1}=d_{2}=0.3, \quad V_{\mathrm{f}}=0.6 \quad$ and (d) $d_{1}=d_{2}=0.3, V_{\mathrm{f}}=0.4$. 
reinforced epoxy resin matrix (CFRP), shown in figure 6. The curves are identical to GFRP except for the strength values being higher. At $V_{\mathrm{f}}=0.6$, when $d_{2}=0$ the $\sigma_{\mathrm{c}}$ dropped from 2.344 $\mathrm{GPa}$ to $1.75 \mathrm{GPa}$. In comparison the drop was from $1.59 \mathrm{GPa}$ to $1.198 \mathrm{GPa}$ at $V_{\mathrm{f}}=0.4$. Contrary to the fibres the matrix could accommodate much higher volume fraction of defects and up to $30 \%$ showed virtually no strength deterioration in all cases of fibre to matrix ratios. When the volume fraction of fibres was raised from $25 \%$ to $70 \%$ (figure 6), with increasing defect concentration, the slopes of $\sigma_{\mathrm{c}}$ increased from 0.0093 to 0.00986 . The difference although being not much but significant. This is reflected in figure 7 where the values of the slopes are drawn against vol.\% fibres. A break in the slope was evident, indicative of two different failure modes being operative at below and above $40 \%$ fibre concentration.

Figure 8 shows the variation in composite strength properties with different resin matrices (table 2) reinforced with carbon fibre at $V_{\mathrm{m}}=0.4$ and 0.6 having none and $30 \%$ defects. At no defect in the resin matrix the strength value was $2.33 \mathrm{GPa}$ against $1.72 \mathrm{GPa}$ at $30 \%$ defect concentration when $V_{\mathrm{f}}=0.6$. At $V_{\mathrm{f}}=0.4$ the composite strength values were $1.56 \mathrm{GPa}$ and $1.17 \mathrm{GPa}$ at zero and $30 \%$ defect concentrations, respectively.

The situation was not the same when different fibre strength values were taken (table 2). Figure 9 shows that the composite strengths increased with the fibre strengths and were maximum at zero defect levels in fibre as well as in epoxy resin.

\section{Conclusion}

The modified rule of mixtures as developed in (5) demonstrate a mean to estimate a more realistic properties of a composite having known concentration of defects in the reinforcing fibres and matrix material. The defect levels up to $30 \%$ in the resin matrix has virtually no effect on the composite strength whereas a small volume $\%$ of defects in the fibre affects the strength very seriously. Two different failure modes were envisaged at below and above $40 \%$ fibre reinforcement in the composite. The equation is equally applicable for estimating any other property of composites, physical or thermal, having defects in any form.

\section{Acknowledgements}

I wish to thank my scholars for their help in data collection and the inspiration for this development. My parent body CSIR, HRD is acknowledged for providing the necessary funds and Director, IACS, for the facilities.

\section{References}

Bailey J E and Barker H A 1971 Ceramics in severe environments (eds) W W Krigel and H Palmour III (New York: McGraw-Hill) p. 5

Black W B 1980 Ann. Rev. Mater. Sci. 10311

Chamis C L 1987 J. Reinf. Plastic \& Comp. 6268

Chow T W and Kelly A 1980 Ann. Rev. Mater. Sci. 10229

Dhingra A K 1980 Philos. Trans. R. Soc. London A294 411

Gagin I V 1980 Canadian Clay Ceram. 5310

Johnson J W 1980 Philos. Trans. R. Soc. London 294487

Johnson W and Ghose S K 1981 J. Mater. Sci. 16285

Jones R M 1975 Mechanics of comp. mater. (New York: McGraw-Hill)

Kelly A and Mileiko S T 1983 Fab. of comp. (Amsterdam: North Holland)

Matsumoto T 1985 Pure \& Appl. Chem. 71553

Monteiro H A 1986 Popular Plastics 3120

Muzzy J D and Kayo A O 1984 Polym. Comp. 5169

Okamura K, Sato M and Hasegawa Y 1987 Ceram. Int. 1355

Padmanabhan K and Kishore A 1995 Composites 26201

Spencer A 1986 Comp. Sci. \& Technol. 2793

Watkinson K, Thomas A and Bevis M 1982 J. Mater. Sci. 17 347

Weibull W 1951 J. Appl. Mech. 18293

Yajima S, Okamura K, Hayashi J and Omori M 1976 J. Am. Ceram. Soc. $\mathbf{5 9} 324$

Zweben C and Rosen B W 1970 J. Mech. Phys. Sol. 18189 